\title{
Twenty years of the Armenian Astronomical Society (ArAS)
}

\author{
A. M. Mickaelian ${ }^{*}$ S. V. Farmanyan, and G. A. Mikayelyan \\ NAS RA V. Ambartsumian Byurakan Astrophysical Observatory (BAO), Byurakan 0213, Aragatzotn province, Armenia
}

\begin{abstract}
A review on the activities and achievements of the Armenian Astronomical Society (ArAS) and the Armenian astronomy in general is given on the occasion of the $20^{\text {th }}$ anniversary of the official foundation of ArAS. ArAS membership, ArAS electronic newsletters (ArASNews), ArAS webpage, Annual Meetings, Annual Prize for Young Astronomers (Yervant Terzian Prize) and other awards, international relations, participation in international organizations, Byurakan International Summer Schools (BISS), regional and local schools, Byurakan science camps, astronomical Olympiads and other events, other matters related to astronomical education, astronomical heritage, amateur astronomy, astronomy outreach and ArAS further projects are described and discussed.
\end{abstract}

Keywords: Armenian Astronomical Society - electronic newsletter - annual meeting - summer schools science camps - astronomical school lectures - annual prize - astronomical heritage - astronomical education - outreach.

\section{Introduction}

The Armenian Astronomical Society (ArAS) was in fact created on 22 June 1999, when the first database of Armenian astronomers was collected, it was decided to create the society, By-Laws were developed and ArAS founding meeting was held. It is true that the Society was officially registered by the Armenian Ministry of Justice in two years, on 29 August 2001. Anyway, before that, actions were taken to involve astronomers in the membership, identify and organize the future activities of ArAS. After the official registration, the first steps were the affiliation to the European Astronomical Society (EAS) in September 2001, the creation of ArAS website in 2002, preparation and distribution of electronic newsletters ("ArASNews") since 2002 and establishment of the ArAS annual meetings since 2002. Since then, almost all events in Armenian astronomy are to a large extent connected with ArAS, and in the 2000s Armenian astronomy by its activeness has reached and in some ways exceeded the previous successes present during the Soviet Union years.

ArAS reports have also been published in some other papers (Mickaelian 2014, 2016, Mickaelian \& Farmanyan 2018, Mickaelian et al. 2019, 2020).

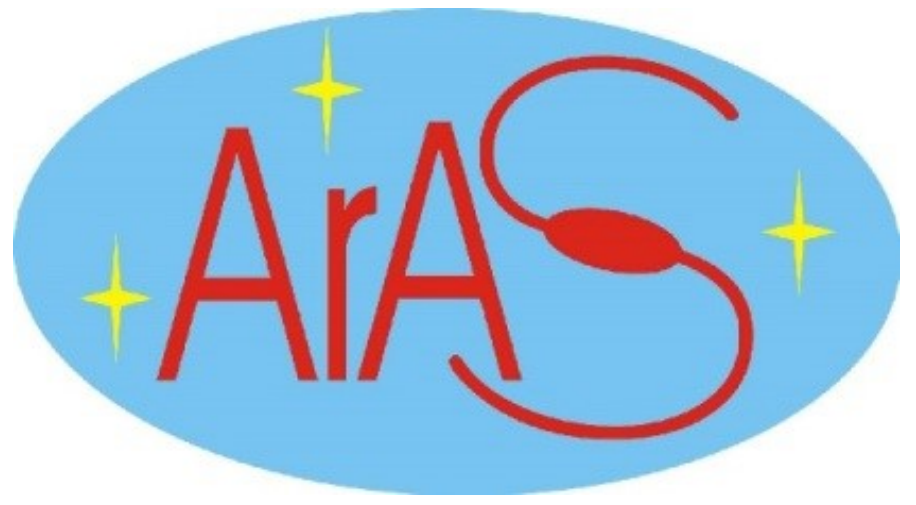

*aregmick@yahoo.com 


\section{Membership}

ArAS is an organization of exclusively professional astronomers (though a few exceptions are allowed), and also aims at establishing close ties with the Armenian foreign astronomers, inviting them to join and cooperate with astronomers in Armenia. ArAS founding members were 16 astronomers of the Byurakan Astrophysical Observatory (BAO). ArAS currently has 95 members (including 13 founding ones) representing 49 institutions from 21 countries (http://www.aras.am/Members/members.html), including: Armenia - 48 (BAO - 29, YSU -4 and others), USA - 13, Germany - 6, Russia - 5, France -3 , Mexico - 3, Italy and Spain - 2 (each), Bulgaria, Canada, Chile, Greece, Hungary, India, Ireland, Netherlands, Portugal, Romania, Switzerland, Thailand, and UK - 1 (each). Among the famous ArAS members there are Michel Mayor (Switzerland), Brent Tully (USA), Vahe Petrosian (USA), Daniel Weedman (USA), Igor Karachentsev (Russia), Daniel Kunth (France), Massimo Turatto (Italy) and many others. We have created for each member a personal webpage containing basic information on his personal and professional data. ArAS has 2 Co-Presidents: Haik Harutyunian and Areg Mickaelian (Acting President), ArAS Vice-President: Tigran Magakian, ArAS Scientific Secretary: Elena Nikoghosyan, Treasurer: Marietta Gyulzadyan, ArASNews Editor: Meline Asryan, and ArAS Webpage Administrator: Gor Mikayelyan.

\section{ArAS Electronic Newsletter}

Until recently ArAS released periodically electronic newsletters (ArAS Newsletters, ArASNews; http: //www.aras.am/ArasNews/arasnews.html) typically 8 times in a year (periodicity of 1.5 month). The Editors have been: Tigran Magakian (2002-2004, issues \#1-12), Lusine Sargsyan (2005, issues \#13-16), Lilit Hovhannisyan (2006-2007, issues \#17-24), Areg Mickaelian (2008-2014, issues \#25-76), Sona Farmanyan (2015-2020, issues \#77-117) and Meline Asryan (since 2021, issues \#141-145). Since 2015 the Newsletter became monthly, 12 issues in a year (however, in 2018-2020 it was mostly not published). In total, including the beginning of 2021, 122 issues have been prepared and released. In all ArASNews, already more than 1000 articles have been published with total some 1700 pages. ArAS Newsletters give news, announcements, articles on Armenian astronomy and BAO, ArAS new members, international and local meetings, summer/winter schools and participation of Armenian astronomers in them, astronomical education in Armenia, Armenian archaeoastronomy and astronomy in culture, anniversaries, scientific, scientific-popular, information materials, etc. A Reference List of ArASNews articles (http: //www.aras.am/ArasNews/arasnewsreference.html) has been also created allowing easy access to all articles related to any subject.

\section{ArAS webpage}

ArAS webpage (http://www.aras.am/) was created in February 2002, at first to give the necessary information about ArAS, including ArAS objectives and forms of activities, list of ArAS members, annual meetings and other events, etc.
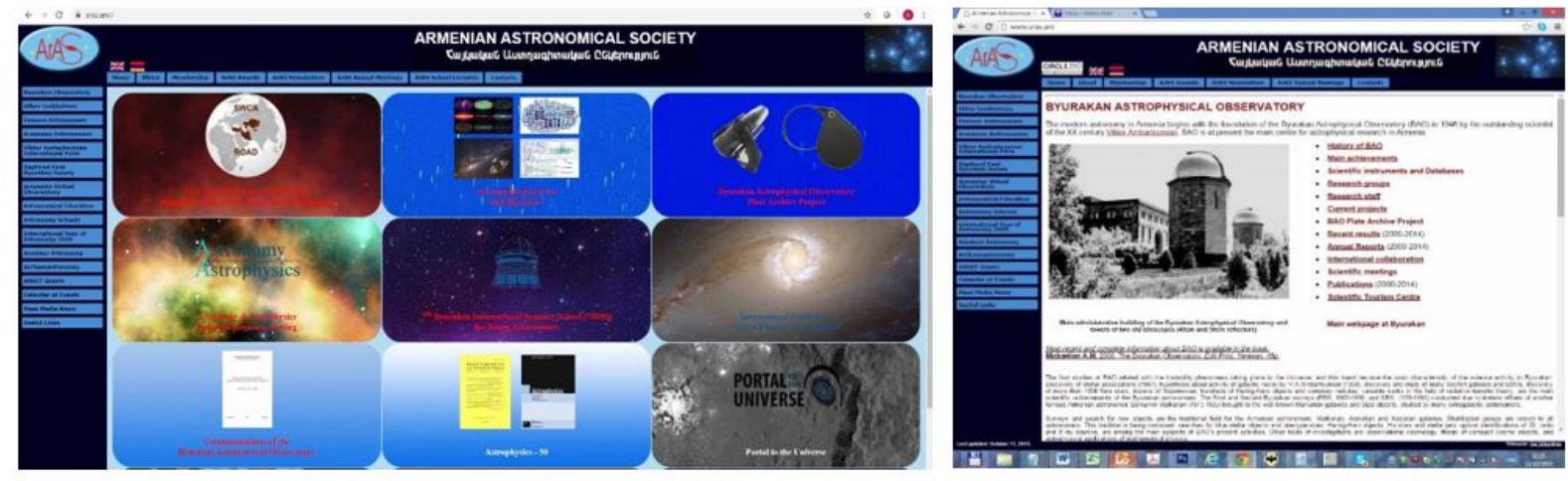

In early 2009, in connection with the International Year of Astronomy (IYA-2009), ArAS webpage was fundamentally enriched and renewed and became a repository containing full information on Armenian astronomy. There is information about BAO history, achievements, current projects and international collaboration, received grants, all publications since 2000 have been installed, all meetings with individual 
pages, new sections have been opened for other scientific institutions in Armenia related to astronomy, 21 famous Armenian astronomers, database of 257 Armenian astronomers throughout the world, astronomical education, amateur astronomy, archaeoastronomy, etc. Without any exaggeration, in terms of the amount of information, ArAS webpage is the richest one among all Armenian scientific organizations and one of the best in the world. We also published in ArAS website Calendars of Astronomical Events of 2014-2021.

\section{Participation in international organizations}

Armenia is one of 82 member-states of the International Astronomical Union (IAU), as well as ArAS is recognized by IAU. Areg Mickaelian is the Secretary and the Acting President of the IAU National Committee for Astronomy (NCA) in Armenia. ArAS is one of EAS 28 affiliated societies, and by its activities it seconds only the most powerful countries in Europe: UK, Germany, France, Italy and some others. ArAS is also the official representative of the Euro-Asian Astronomical Society (EAAS) in Armenia. Areg Mickaelian is one of the EAAS Vice-Chairs and is a member of the EAAS International Bureau, and Tigran Magakian is a member of the EAAS Scientific-Technical Committee. Together with the Ministry of Education, Science, Culture, and Sports, ArAS is also one of the official representatives of International Astronomical Olympiads (IAO) in Armenia. Armenia joined the international Galileo Teachers Training Program (GTTP) with its official representatives Areg Mickaelian (Ambassador in Armenia) and Marietta Gyulzadyan (Armenian Coordinator). Armenia is an associate member of the Sub-Regional European Astronomical Committee (SREAC) acting in Southeast Europe and an associate member of the International Planetary Data Alliance (IPDA). The last EAS Annual Meeting (European Week of Astronomy and Space Science, EWASS) was virtually held in 2021; ArAS Acting President Areg Mickaelian and other Armenian astronomers took part from Armenia.

\section{ArAS awards}

ArAS has 5 kinds of awards given at ArAS webpage (http://www.aras.am/Prize/awards.htm):

- ArAS Annual Prize for Young Astronomers (Yervant Terzian Prize) (since 2004)

- ArAS/BAO Awards (2009)

- ArAS Certificates

- Scientific Journalism Prizes (since 2009), including ArAS/OxArm (Oxford Armenian Society) awards in 2011

- Galileo Teachers Training Program (GTTP) Certificates (since 2011)

Since 2004, ArAS awards Annul Prize for Young Astronomers (since 2009 it was renamed to Yervant Terzian Prize). It is being awarded to the most active young astronomers (younger 35) taking into account all annual activities. The award is sponsored by ArAS Co-President Prof. Yervant Terzian and BAO. At present it totals USD 500, and it is being awarded with ArAS Certificate. The full list of ArAS Annual Prize is given below:

In 2020, the GTTP international certificates was awarded to Ewelina Gradzka (Poland) who organized 2 events in Armenia: "Young Explorers Club" and "Under Armenian Sky".

\section{ArAS meetings and other events}

Since 2002, ArAS holds regular annual meetings, however some of them were associated or combined with other conferences and events, where ArAS acted as co-organizer.

ArAS XIII annual meeting was unprecedented in its theme. It took place on 7-10 October 2014 in Byurakan and was called "Relation of Astronomy to Other Sciences, Culture and Society" (RASCS, http:// www.aras.am/Meetings/RASCS/index.html). In addition to astrophysical issues it included Philosophical Problems of Astronomy, Astrobiology, Astroinformatics, Astronautics, Archaeoastronomy, Astronomical Education, Amateur Astronomy, Scientific Tourism and other topics related to astronomy. It brought together astronomers, philosophers, historians, archeologists, philologists, artists and representatives of other fields. ArAS dedicates small-scale events (one-day conferences or seminars) to the anniversaries of famous astronomers. 


\begin{tabular}{|l|l|l|l|}
\hline Year & Winners & Affiliation & Country \\
\hline 2020 & Hasmik ANDREASYAN / Gor MIKAYELYAN & BAO / BAO & Armenia / Armenia \\
\hline 2019 & Naira AZATYAN & BAO & Armenia \\
\hline 2018 & Sona FARMANYAN & BAO & Armenia \\
\hline 2017 & Naira AZATYAN & BAO & Armenia \\
\hline 2016 & Anahit SAMSONYAN & BAO & Armenia \\
\hline 2015 & Artur HAKOBYAN & BAO & Armenia \\
\hline 2014 & Gurgen PARONYAN & BAO & Armenia \\
\hline 2013 & Hayk ABRAHAMYAN / Avet HARUTYUNYAN & BAO / TNG & Armenia / Italy \\
\hline 2012 & Vardan ADIBEKYAN & CAUP & Portugal \\
\hline 2011 & Marine AVTANDILYAN & YSPU & Armenia \\
\hline 2010 & Parandzem SINAMYAN & BAO & Armenia \\
\hline 2009 & Lusine SARGSYAN & BAO & Armenia \\
\hline 2008 & Vardan ADIBEKYAN / Artur HAKOBYAN & BAO / BAO & Armenia / Armenia \\
\hline 2007 & Igor CHILINGARIAN & SAI MSU / CRAL & Russia / France \\
\hline 2006 & Lilit HOVHANNISYAN / Parandzem SINAMYAN & BAO / BAO & Armenia / Armenia \\
\hline 2005 & Artak HARUTYUNYAN / Elena HOVHANNESSIAN & BAO / BAO & Armenia / Armenia \\
\hline 2004 & Lusine SARGSYAN & BAO & Armenia \\
\hline
\end{tabular}

\section{Summer Schools and Science Camps}

Since 2006, ArAS and BAO organize regular Byurakan International Summer Schools (BISS, http: //www.aras.am/Meetings/meetingsSummerSchools.html), once every two years. In 2018, during the IAU General Assembly XXX in Vienna, Austria, BISS were announces as one of the top-3 international astronomical schools (along with ISYAs and Vatican Observatory Summer Schools, VOSS). Since 2005, local summer schools for YSU Physics Department students are being organized to cause and increase interest to astronomy. They are the continuation of the initiative started in 1995. ArAS has also organized a Conference for Young Astronomers in 2011. A Regional Astronomical Summer School (RASS) on Space Sciences and Technologies was organized in 2019 to establish the Armenia's first steps to this area. RASS also became a series and the $2^{\text {nd }}$ one was organized in 2021 .

Armenian young astronomers regularly attend several international schools and conferences: IAU International Schools for Young Astronomers (ISYA), European NEON/OPTICON schools, Vatican Observatory Summer Schools (VOSS), Virtual Observatory (VO) training schools, and a number of others. ArAS website holds a directory table of the most important regular international schools (http: //www.aras.am/SS2010/ss_other_schools.htm) which helps young astronomers and students to follow and find their respective schools based on the level of the students, location, subject, etc.

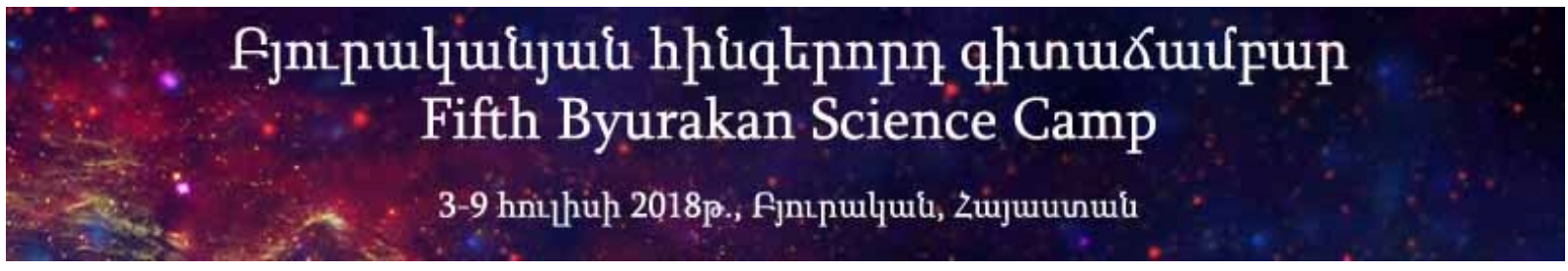

Since 2014, on the initiative of Sona Farmanyan, ArAS also organizes Byurakan Science Camps (BSC) for school pupils aged 12-15. Fund for Armenian Relief (FAR) partially sponsors these camps. In 2021, the $7^{\text {th }}$ Byurakan Science Camp (7BSC) was organized.

\section{Astronomical Olympiads}

Since 1996, International Astronomical Olympiads (IAO) and since 2007, International Olympiads on Astronomy and Astrophysics (IAOO) are being organized. Armenian pupils have regularly taken part in both of them and have achieved excellent results. In total, they have won 10 Gold, 7 Silver and 24 Bronze medals. Marietta Gyulzadyan has especially big contribution in the achievements of our team; she has been the team leader since 2006. Among the most successful participants are: Zhirayr Avetisyan and Mkrtich Soghomonyan (each have won one I, one II, and one III rank prizes), Tigran Shahverdyan (one II and one III rank prizes), Tigran Nazaryan, Hayk Saribekyan, Hayk Tepanyan, Hayk Hakobyan and Edgar Vardanyan have one I rank prize each. Igor Chilingarian from Russia has won I rank prize as well. 
Twenty years of ArAS

\begin{tabular}{|l|l|l|}
\hline Year & No. & ArAS annual meeting description and other related conferences \\
\hline 2002 & I & Scientific Sessions and Annual Report \\
\hline 2003 & II & Scientific Sessions combined with Armenian-Georgian Colloquium \\
\hline 2004 & III & Scientific Sessions and Annual Report \\
\hline 2005 & IV & Scientific Sessions and Annual Report \\
\hline 2006 & V & Scientific Sessions combined with BAO $60^{\text {th }}$ Anniversary Meeting \\
\hline 2007 & VI & Scientific Sessions combined with $15^{\text {th }}$ EAS Annual Meeting (JENAM-2007) \\
\hline 2008 & VII & Scientific Sessions combined with Ambartsumian's 100 ${ }^{\text {th }}$ Anniversary Meeting \\
\hline 2009 & VIII & Scientific Sessions related to IYA-2009 (incl. Astrobiology and Archaeoastronomy) \\
\hline 2010 & IX & Scientific Sessions and Annual Report \\
\hline 2011 & X & Scientific Sessions and Annual Report \\
\hline 2012 & XI & Scientific Sessions combined with Anania Shirakatsi 1400 meeting \\
\hline 2013 & XII & Annual Report and Summary of Astronomical Year 2013 \\
\hline 2014 & XIII & Scientific Sessions combined with RASCS meeting \\
\hline 2015 & XIV & Scientific Sessions combined with Armenian-Iranian Astronomical Workshop \\
\hline 2016 & XV & Annual Report and Summary of Astronomical Year 2016 \\
\hline 2017 & XVI & $\begin{array}{l}\text { Scientific Sessions combined with the International Conference } \\
\text { "Astronomical Heritage of the Middle East" }\end{array}$ \\
\hline 2018 & XVII & IAU South West and Central Asian $2^{\text {nd } \text { Regional Astronomical Workshop }}$ \\
\hline 2019 & XVIII & IAU South West and Central Asian $3^{\text {rd } \text { Regional Astronomical Workshop }}$ \\
\hline 2020 & XIX & $\begin{array}{l}\text { Scientific Sessions combined with the International Symposium } \\
\text { "Astronomical Surveys and Big Data } 2^{\text {" }}\end{array}$ \\
\hline 2021 & XX & BAO seminar on ArAS 20-years celebration \\
\hline
\end{tabular}

\section{ArAS School Lectures}

ArAS Co-President Yervant Terzian and some other American sponsors of Armenian origin, co-finance a program of ArAS School Lectures, which runs jointly with the Armenian Ministry of Education and Science (MES). The lecturers are professional astronomers and their visits leave vivid impression for the school children. Schools are also given astronomical materials (books, booklets, sky maps, calendars, etc.), connection is being established with gifted children. In 2012, 2013, 2014, 2016, 2018, 2019, 2020 and 2021 such a program was implemented in Armenia and Artsakh schools.

\section{Other matters of astronomical education}

Armenia actively participates in the IAU Astronomy Education programs. The IAU Office for Astronomy Education (OAE) has been established in Heidelberg, Germany. The Armenian National Astronomy Education Coordinator Team (NAEC Team) consists of: Marietta Gyulzadyan, Sona Farmanyan and Armine Patatanyan.

ArAS tries to contribute to the astronomical education matters in Armenia. Summer Schools, Science Camps and Olympiads are also in this field. Network for Astronomy School Education (NASE) program was implemented in Armenia in 2019. Projects "Under the Common Skies" and "Young Explorers Clubs" were organized in 2018 and 2019 in collaboration with Poland (Ewelina Gradzka) and support from the USA. Other activities include installation of various information on ArAS webpage, preparation and release of educational CD/DVDs (recently released "Astronomy for schools" and "Astronomy for students" DVDs, which are collections of astronomical textbooks, books, dictionaries, encyclopedias, articles, reports, photos, videos, software, etc.). In November 2014, on the initiative of Sona Farmanyan ArAS founded Facebook group “Junior Astronomer's Club" (JAC). "Viktor Ambartsumian's Descendants" Educational Charitable Foundation was founded in August 2014. 


\begin{tabular}{|l|l|l|}
\hline Year & Summer school name & Short \\
\hline 2005 & $1^{\text {st }}$ Byurakan Summer School for YSU PhysDep students & 1 BSS \\
\hline 2006 & $1^{\text {st }}$ Byurakan International Summer School & 1 BISS \\
\hline 2008 & $2^{\text {nd }}$ Byurakan International Summer School & 2 BISS \\
\hline 2009 & $2^{\text {nd }}$ Byurakan Summer School for YSU PhysDep students & 2 BSS \\
\hline 2010 & $\begin{array}{l}3^{\text {rd }} \text { Byurakan International Summer School / } \\
\text { IAU International School for Young Astronomers }\end{array}$ & 3 BISS/ISYA \\
\hline 2011 & FSU countries Young Scientists Conference & FSU-YSC \\
\hline 2012 & $4^{\text {th }}$ Byurakan International Summer School & 4 BISS \\
\hline 2013 & $3^{\text {rd }}$ Byurakan Summer School for YSU PhysDep students / IAU S304 training & 3 BSS \\
\hline 2016 & $5^{\text {th }}$ Byurakan International Summer School & 5 BISS \\
\hline 2018 & $6^{\text {th }}$ Byurakan International Summer School & 6 BISS \\
\hline 2019 & Regional Summer School on Space Sciences and Technologies & 1 RASS \\
\hline 2020 & $7^{\text {th }}$ Byurakan International Summer School & 7 BISS \\
\hline 2021 & $2^{\text {nd }}$ Regional Astronomical Summer School & 2RASS \\
\hline
\end{tabular}

\section{Archaeoastronomy and Astronomy in Culture}

To coordinate issues related to Archaeoastronomy, an appropriate section was opened on ArAS webpage (http://www.aras.am/Archaeoastronomy/astronomyancientarmenia.html). These questions are currently given great importance in the world, in particular, they are in the focus of international organizations such as UNESCO ( "Astronomy and World Heritage" project), IAU (Working Group "Astronomy and World Heritage"), International Council of Monuments and Sites (ICOMOS), European Society for Astronomy in Culture (Société Européenne pour l'Astronomie dans la culture, SEAC), "Starlight" initiative and others. In 2014, IAU created a new working group (WG) "Archaeoastronomy and Astronomy in Culture" (AAC). Already several related meetings have been organized in Armenia in 2011, 2012, 2014, 2015, 2016, 2017 and 2021. ArAS Newsletter now has a permanent section "Archaeoastronomy and Astronomy in Culture". Areg Mickaelian is an Organizing Committee member of the newly founded (in 2018) IAU WG "Astronomy and World Heritage".

\section{Astronomy outreach}

Armenia actively participates in the IAU Astronomy for Development (we have established a regional office in Armenia; see the corresponding article) and Astronomy Outreach programs. The IAU Office for Astronomy Outreach (OAO) has been established in Tokyo, Japan. The Armenian National Coordinator of the latter for a number of years has been Sona Farmanyan and recently Lilit Darbinyan also joined.

ArAS gives importance to the development of amateur astronomy. There is "Goodricke John" amateur astronomers organization created by Ruben Buniatyan, which put efforts and reached the recognition of 18 September (Viktor Ambartsumian's birthday) as Astronomy Day in Armenia since 2009. ArAS created on its webpage a section for amateur astronomy (further to establish Armenian Amateur Astronomical Society, ArAAS), as well as a Facebook group, where one can register as an amateur astronomer.

In December 2010, to promote scientific, especially astronomical journalism, the group of Scientific Journalists in Armenia was formed, which includes more than 160 journalists. ArAS periodically prepares and disseminates press releases, organizes press conferences, interviews, and scientific journalism seminars. Press releases contain astronomical news, events organized by ArAS and BAO and held in BAO, occurred and expected celestial phenomena, as well as scientists anniversaries, Armenian and other international scientific news. Astronomers hold public lectures at different organizations. On ArAS webpage, online "Astghagitak" ("Astronomy Expert") popular astronomical journal was created, where materials in Armenian are being placed for those interested in astronomy.

ArAS publishes a number of books (Proceedings of its Annual Meetings), popular booklets, calendars, sky maps and other promotional material. 

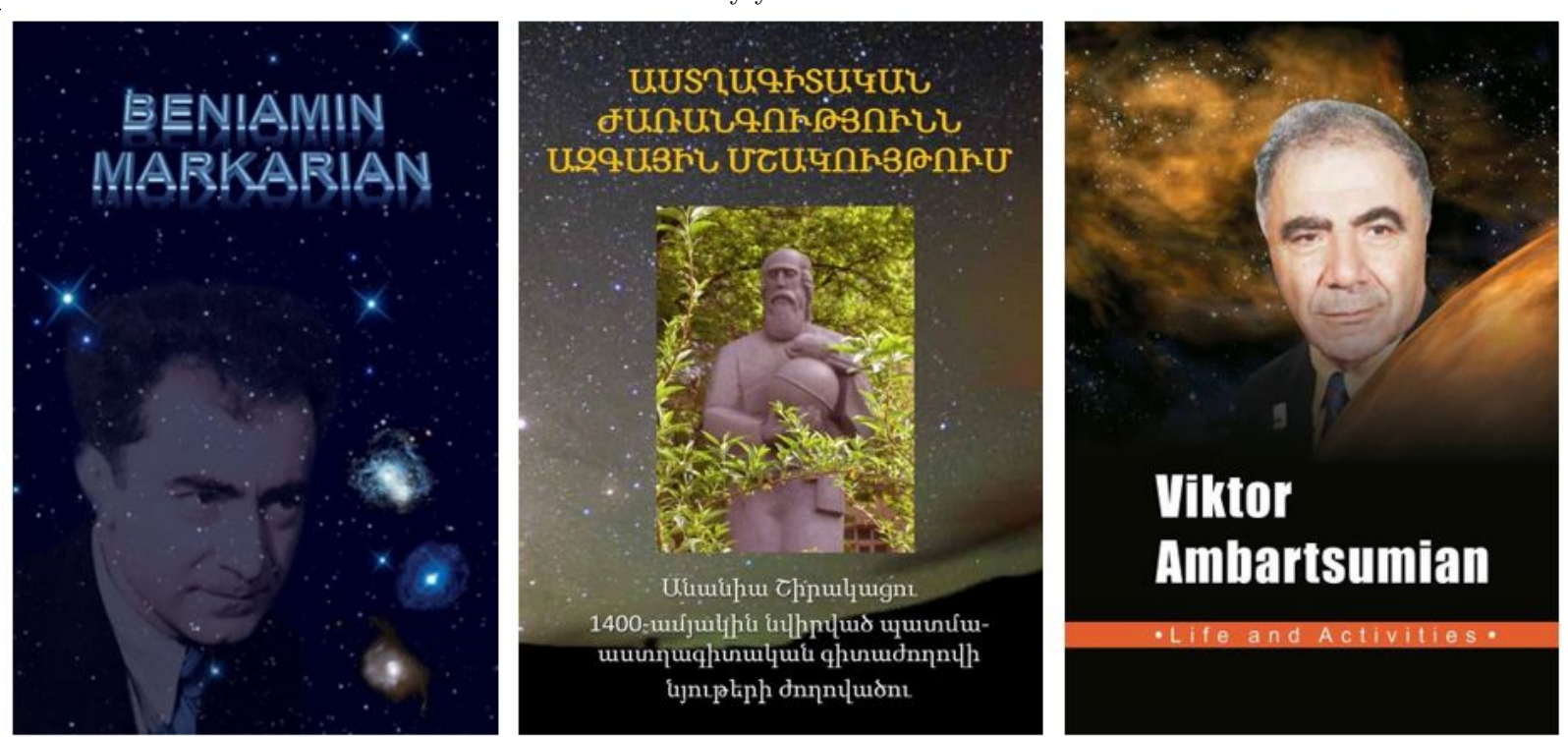

\section{Further plans}

More serious attention should be paid to "Astronomy and World Heritage" program. In particular, it is planned to implement a global program on Archaeoastronomy and History of Astronomy, Astronomy in Culture, as well as global programs on Amateur Astronomy and Astronomy Education. In parallel to the UNESCO World Heritage list, the IAU WG "Astronomy and World Heritage" has established a list of Outstanding Astronomical Heritage $(\mathrm{OAH})$, and our aim is to include in it a number of Armenian astronomical items, particularly the Armenian ancient calendar and chronology, Armenian astronomical rock art, Zorats Karer (or Karahunge, the "Armenian Stonehenge"), Metzamor Hill astronomical platform, Anania Shirakatsi's astronomical heritage, and the architectural ensemble of the Byurakan Astrophysical Observatory (BAO).

Yet in deficient condition is the amateur astronomy; amateur telescopes, observational programs, amateur astronomers meetings, educational programs, and wider publicizing of astronomy are needed. Global programs are aimed at coordinating the whole area in Armenia. We intend to create new sections on ArAS webpage, namely Armenian duplicates of the "Portal To The Universe" (PTTU) and other webpages.

\section{References}

Mickaelian A. M., 2014, in Harutyunian H. A., Mickaelian A. M., Parsamian E. S., eds, Vol. 1400, Astronomical Heritage in the National Culture. pp 198-212

Mickaelian A. M., 2016, in Mickaelian A. M., Khosroshahi H. G., Harutyunian H. A. E. ., eds, Proceedings of Armenian-Iranian Astronomical Workshop (AIAW). pp 37-45

Mickaelian A. M., Farmanyan S. V., 2018, Communications of the Byurakan Astrophysical Observatory, 65, 99

Mickaelian A. M., Farmanyan S. V., Mikayelyan G. A., 2019, in Farmanyan S. V., Mickaelian A. M., McKim Malville J., Bagheri M., eds, Astronomical Society of the Pacific Conference Series Vol. 520, Astronomical Heritage of the Middle East. p. 295

Mickaelian A. M., Farmanyan S. V., Mikayelyan G. A., 2020, Communications of the Byurakan Astrophysical Observatory, 67,75 